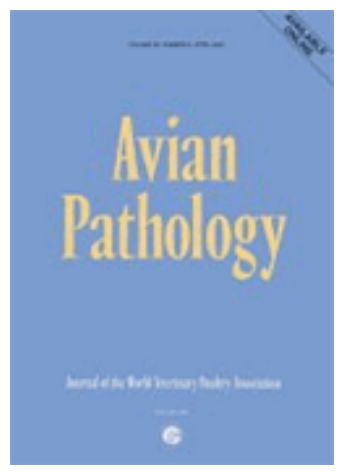

\title{
Comparison of the efficacy of four antimicrobial treatment schemes against experimental Ornithobacterium rhinotracheale infection in turkey poults pre-infected with avian pneumovirus
}

\begin{tabular}{|r|l|}
\hline Journal: & Avian Pathology \\
\hline Manuscript ID: & CAVP-2006-0034.R1 \\
\hline Manuscript Type: & Original Research Paper \\
\hline Author: & 06-Mar-2006 \\
\hline Complete List of Authors: & $\begin{array}{l}\text { Marien, Maja; Faculty of Veterinary Medicine, Bacteriology } \\
\text { Nauwynck, Hans; Faculty of Veterinary Medicine, Ghent University, } \\
\text { Laboratory of Virology } \\
\text { Duchateau, Luc; Faculty of Veterinary Medicine, Ghent University, } \\
\text { Department of Physiology and Biometrics } \\
\text { Martel, An; Faculty of Veterinary Medicine, Ghent University, } \\
\text { Department of Pathology, Bacteriology and Avian Diseases } \\
\text { Chiers, Koen; Faculty of Veterinary Medicine, Ghent University, } \\
\text { Department of Pathology, Bacteriology and Avian Diseases } \\
\text { Devriese, Luc; Faculty of Veterinary Medicine, Ghent University, } \\
\text { Department of Pathology, Bacteriology and Avian Diseases } \\
\text { Froyman, Robrecht; Bayer HealthCare AG, Animal Health Division } \\
\text { Decostere, A; Faculty of Veterinary Medicine, Ghent University, } \\
\text { Department of Pathology, Bacteriology and Avian Diseases }\end{array}$ \\
\hline Keywords: & $\begin{array}{l}\text { Ornithobacterium rhinotracheale, avian pneumovirus, antibiotic } \\
\text { treatment, turkeys }\end{array}$ \\
\hline
\end{tabular}

\section{SCHOLARONE Manuscripts}


Author's responses to the comments by the editor and the referees concerning the paper "Comparison of the efficacy of four antimicrobial treatment schemes against avian pneumovirus and Ornithobacterium rhinotracheale dual infection in turkeys".

As suggested by the editor we revised the manuscript according to the referee's comments, and the manuscript was read through by someone with English as first language and corrected where needed.

\section{Response to comments by Referee 1:}

- Although the goal of the experiment was to determine the efficacy of antimicrobial treatment against ORT, the birds were indeed infected first with APV. The reason for this is that clinical scores were included as a parameter for the evaluation of the efficacy of the antimicrobials and it had been demonstrated in a previously conducted experiment that infection with ORT alone did not cause clinical signs. Priming with APV, however, resulted in obvious clinical signs. Also, in the field, infections with ORT are often preceded by infections with APV. Marien, M., Decostere, A., Martel, A., Chiers, K., Froyman, R. \& Nauwynck, H. (2005). Synergy between avian pneumovirus and Ornithobacterium rhinotracheale in turkeys. Avian Pathology, 34 (3), 204-211.

- Response to the referee's comments about the statistical design: Although the birds were indeed followed up until $15 \mathrm{dpbi}$, as expected, all clinical scores returned to zero from day 10 onwards. We intended to perform two preplanned comparisons. A first comparison, based on area under the curve 
between 0 and 5 dpbi enabled us to observe the early effects of the infection. Furthermore, at this time, all animals (15 per group) were still available, which was no longer the case after that day. A second comparison was aimed at investigating the evolution over time from 0 to 9 dpbi. This enabled us to understand how the infection evolves over time, and furthermore to study whether the treatment groups differ in this period with respect to the clinical score. We understand that all this may not have been very clear to the reader, and therefore have clarified this in the text (lines 198-200).

$\underline{\text { Title }}$

- According to the referee's suggestion, the title has been adjusted to the following: "Comparison of the efficacy of four antimicrobial treatment schemes against experimental Ornithobacterium rhinotracheale infection in turkey poults pre-infected with avian pneumovirus".

Materials and methods

- Line 91 (lines 92-97): The in-house serum neutralization test has been described in the manuscript as requested.

- Line 99-100 (lines 105-107): This sentence has been adjusted according to the referee's comment.

- Lines 103-106 (lines 109-116): The method of the preparation of the inoculation suspension has been described more precisely, as requested by the referee.

- Line 106-108 (line 118): The reference for the MIC values has been specified as requested.

- Lines 110-113 (lines 120-124): We supplied some extra information about the drugs used in the study as requested by the referee. It should be noted that, 
currently, in Europe, as far as we know, there are no registered antimicrobials for which ORT specifically is an indication.

- Lines 151-157 (lines 162-168): In preliminary experiments, we determined that the average weight of mucus absorbed by a swab was $200 \mu \mathrm{g}$. This amount was subjected to minimal variation.

- Lines 158-159 (lines 170-172): This sentence has been adapted according to the comments of the referee.

- Lines 177-179 (lines 191-195): The requested information is provided in the text.

- Line 262 (line 185 and line 285): This is adapted to the referee's comment.

\section{$\underline{\text { Results and Discussion }}$}

- The response to the referee's comments about the statistical design was already dealt with above.

- We decided not to show all the data in the figures to maximize clarity. Since no more clinical signs were observed from 10 dpbi onwards (mentioned in lines 220-221), and no more ORT organisms could be retrieved from the tracheal swabs from 11 dpbi onwards (mentioned in lines 238-239), we decided to leave out the results from after these dates so that the figure could be clearer on the whole.

- There were no criteria for the selection of the five birds per group that were euthanised at 5 dpbi. It was randomly determined in advance which animals were going to be killed. We clarified this in the manuscript in line 154 . Furthermore, we can say that the clinical signs were very similar in terms of severity in all birds of one group. We added this information in the manuscript in lines 253-254. 
- In response to the referee's comments concerning the body weight at the start of the experiment, we would like to say that the initial body weight was taken into account in the statistical analysis of the final body weight. A correction was made for the difference in initial body weight (see lines 209-210). We therefore do not think it is necessary to provide the actual figures of the initial body weight, as this would unnecessarily lengthen the manuscript.

- The referee indeed raises a justified question as to whether other bacteria (e.g., E. coli) were isolated from the experimental birds rather than ORT. We cannot exclude the possibility that other bacteria, although undetected, might have been present. The animals were SPF and kept in separate HEPA-filtered isolation rooms. In this experiment we isolated the ORT bacteria on a selective medium containing $5 \mu \mathrm{g} / \mathrm{ml}$ gentamicin en polymyxin to suppress the growth of contaminating bacteria.

- In line 217 we specifically mentioned that mortality was not observed during the experiment.

- Basic Pharmacokinetics, 1999, University of Manchester, M. Rowland: "The apparent volume of distribution at steady state $\operatorname{Vd}(s s)$ (equilibrium) is the pharmacokinetic parameter that relates the amount of drug in the body (A) to the concentration in the plasma or serum $(\mathrm{C}): \mathrm{V}=\mathrm{A} / \mathrm{C}$." The $V d(s s)$ is determined by intravenous injection of a drug after which the concentration in the plasma or serum is measured. This is performed in the same way in the different experiments. To support our statements, we added in the publication the ranges of the $V d(s s)$ as determined in the different experiments (lines 316318). In our publication we tried to explain why the amoxicillin treatment did not show a significant reduction in the parameters assessed in our study, and 
the $V d(s s)$ is one of the pharmacokinetic parameters that has to been taken in account.

- Line 301 (line 321-322): This reference has been deleted.

- Lines 317-318 (lines 336-341): According to Bush (2003) the antibacterial spectrum of amoxicillin is identical to that of ampicillin, and there are few differences in antibacterial activity, especially against Gram-negative bacteria. Furthermore, according to Otten et al. (1975), the difference between ampicillin and amoxicillin lies in the pharmacokinetics of amoxicillin after oral uptake. Therefore, we believe it is permissible to compare ampicillin MIC values to amoxicillin MIC values. We clarified this in the manuscript in lines 341-343.

Bush, K. (2003). B-Lactam antibiotics: penicillins. In Antibiotic and chemotherapy, $8^{\text {th }}$ edition. Finch R.G., Greenwood D., Norrby S.R., and Whitley R.J. (ed.), Churchill Livingstone, New York.

Otten, H., M. Plempel, and W. Siegenthaler. (1975). Neuere Penicilline. In Antibiotika - Fibel. Otten H., Plempel M., and Siegenthaler W. (ed.), Thieme, Stuttgart.

\section{Response to comments by Referee 2:}

- As mentioned above, we altered the title of the manuscript according to the referee's comments.

- In response to the referee's comment that the main finding is that enrofloxacin treatment for three days is more efficacious than enrofloxacin for five days, we have to disagree. It is indeed true that the 3-day enrofloxacin treatment provided overall better results in comparison with the 5-day treatment, but in 
our opinion, this is attributed to the fact that after 2 days of enrofloxacin treatment ORT isolates were found with a higher MIC value. The fact that this rise in MIC value appeared as early as 2 dpbi should make it clear that this also could have taken place in the 3-day treatment group. The observed rise in MIC is most likely not due to the treatment duration (5 days versus 3 days). We tried to clarify this in the manuscript in lines 357-359.

- Figure 2: The reason we wanted to show all the individual values instead of only the mean values was to demonstrate that the rise in mean ORT titres in the enrofloxacin treated groups could be attributed first to a rise in a single animal and gradually in more animals. We also feel that the variation within a specific group is important in the developmental process of an infection model. Therefore, we prefer to show all the points in the figure.

- The different specific remarks made by the referee have been adjusted accordingly. 
2 Comparison of the efficacy of four antimicrobial treatment schemes against

3 experimental Ornithobacterium rhinotracheale infection in turkey poults pre-

4 infected with avian pneumovirus

5

6 Maja Marien, ${ }^{1, *}$ Hans Nauwynck, ${ }^{2}$ Luc Duchateau, ${ }^{3}$ An Martel, ${ }^{1}$ Koen Chiers, ${ }^{1}$ Luc

7 Devriese, ${ }^{1}$ Robrecht Froyman, ${ }^{4}$ \& Annemie Decostere. ${ }^{1}$

8

$9{ }^{1}$ Department of Pathology, Bacteriology and Avian Diseases, Faculty of Veterinary Medicine,

10 Ghent University, Salisburylaan 133, B-9820 Merelbeke, Belgium, ${ }^{2}$ Laboratory of Virology,

11 Faculty of Veterinary Medicine, Ghent University, Salisburylaan 133, B-9820 Merelbeke,

12 Belgium, ${ }^{3}$ Department of Physiology and Biometrics, Faculty of Veterinary Medicine, Ghent

13 University, Salisburylaan 133, B-9820 Merelbeke, Belgium and ${ }^{4}$ Bayer HealthCare AG,

14 Animal Health Division, D-51368 Leverkusen, Germany.

15

16 Short title: antibiotic treatment APV/ORT infection

17

*To whom correspondence should be addressed. Tel: + 32926474 34. Fax: + 32926474

94. E-mail: maja.marien@UGent.be 
27 Comparison of the efficacy of four antimicrobial treatment schemes against experimental

Ornithobacterium rhinotracheale infection in turkey poults pre-infected with avian pneumovirus

\section{Abstract}

The clinical efficacy of drinking-water administration of enrofloxacin for 3 and 5 days, amoxicillin for 5 days and florfenicol for 5 days for the treatment of respiratory disease induced by an experimental Ornithobacterium rhinotracheale $(O R T)$ infection in turkeys preinfected with avian pneumovirus (APV) was assessed based on clinical, bacteriological and histopathological examinations. Experimental groups of 15 susceptible 3-week-old turkeys were each inoculated oculonasally with APV subtype A and three days later with susceptible $O R T$ bacteria. Antimicrobial treatment started one day after $O R T$ inoculation. After infection, the birds were examined and scored for clinical signs, swabbed daily and weighed at different times. Five birds were euthanised and examined for macroscopic lesions at necropsy at 5 days post bacterial inoculation (dpbi), and the remainder at 15 dpbi. Samples of the turbinates, trachea, lungs, air sacs, heart and pericardium were collected for bacteriological and/or histological examination.

Recovery from respiratory disease caused by an APV/ORT dual infection was most successful after enrofloxacin treatment, irrespective of treatment duration, followed by florfenicol. Amoxicillin treatment was not efficacious. Clinical signs and the number of $O R T$ organisms re-isolated from the trachea and the different respiratory organs were significantly reduced by enrofloxacin treatment for 3 and 5 days. ORT bacteria were not re-isolated from the tracheas of the birds treated with enrofloxacin except for one in the 5-day group, as early as one day after medication onset. In the group treated with enrofloxacin for 5 days, ORT organisms with 
51 a higher minimal inhibitory concentration (MIC) value (x 8) were isolated starting two days

52 following treatment onset initially from a single turkey and subsequently from the other 53 animals.

\section{Introduction}

56

57

Viral and bacterial respiratory tract infections frequently occur in diseased turkeys of all ages and may cause considerable financial losses due to reduced growth, an increased mortality rate, high medication costs and a higher number of condemnations at processing (van Empel \& Hafez, 1999).

Ornithobacterium rhinotracheale $(O R T)$ is an infectious pathogen that has been ascribed an etiological role in the respiratory disease complex in turkeys. This Gram-negative bacterium is mostly regarded as a facultatively pathogenic organism, and in field cases, simultaneous isolation of $O R T$, respiratory viruses and/or other bacteria is frequently encountered. One of the viruses judged to have a triggering role is avian pneumovirus (genus Metapneumovirus - MPV) (APV) (van Empel et al., 1996). Recently, in a longitudinal study performed by Van Loock et al. (2005), it was shown that both APV and ORT infections often occur between hatch and slaughter on Belgian turkey farms. In a previous study using an optimized experimental in vivo model, it was demonstrated that $O R T$ following APV inoculation in 3-week-old turkeys has a synergistic effect on the course of respiratory disease (Marien et al., 2005). Dual infection with APV and ORT indeed resulted in more severe clinical signs, macroscopic and histological findings, and a longer persistence of $O R T$ in the respiratory tract compared with the single infections.

Disease caused by $O R T$ may be reduced by preventing predisposing factors including inadequate ventilation, high ammonia levels, too high or too low relative humidity and 
infection with additional pathogenic agents (van Empel \& Hafez, 1999). In practice, however, ORT infections are mostly dealt with using different antibiotics such as amoxicillin, ampicillin, doxycycline, tetracycline, trimethoprim/sulphonamide, enrofloxacin and florfenicol. Hitherto, the actual in vivo efficacy of antibiotics for the treatment of $O R T$ infections in poultry has not yet been investigated. This is to a great extent rooted in the fact that, only until very recently (Marien et al., 2005), no suitable infection model was available. The objectives of the present study are to compare the efficacy of enrofloxacin, amoxicillin and florfenicol for treatment of respiratory disease due to experimental ORT infection in 3week-old turkeys following APV challenge. The efficacy was evaluated on the basis of several parameters, i.e., clinical signs, histopathological findings, re-isolation and titration of the bacterium, and weight gain.

\section{Materials and methods}

Turkeys. Seventy-five specific pathogen free (SPF) turkeys (AFSSA, Ploufragan, France) were used in this study. The turkeys were hatched in our facilities. The birds were housed on litter in separate isolation rooms with HEPA-filtered air, had free access to food and water and received 16 hours of light per day. At two weeks of age the birds were shown to be free from maternally-derived antibodies to ORT and APV by means of an ELISA available commercially (Biochek, Gouda, the Netherlands) and an in-house serum neutralization test, respectively. Neutralization was tested on Vero cells in 96-well cell culture microplates using standard procedures. Briefly, serial twofold dilutions of the sera were made and incubated for $1 \mathrm{~h}$ at $37^{\circ} \mathrm{C}$ with an equal volume of virus suspension (subtype A), containing 100 TCID $_{50}$ APV. The reading was based on the absence or presence of a cytopathic effect over 7 days. 
100 The SN-titres were the reciprocal of the highest serum dilution that inhibited the cytopathic

101 effect in $50 \%$ of the wells.

102

103 Virus. The APV strain A/T6/96 (subtype A) was used. The strain was isolated during a

104 respiratory outbreak on a Belgian turkey farm (Van de Zande et al., 1998). The virus stock

105 had a titre of $5.0 \log _{10} 50 \%$ ciliostatic dose $\left(\mathrm{CD}_{50}\right) / \mathrm{ml}$ after the third passage in tracheal organ

106 cultures.

107

108 Bacterium. The $O R T$ type strain LMG $9086^{\mathrm{T}}$ was used, which was originally isolated from a

109 turkey with a respiratory tract infection. The strain was serotyped as type A in an agar gel

110 precipitation test (Hafez \& Sting, 1999) performed by Professor H. M. Hafez (Institute of

111 Poultry Diseases, Free University of Berlin, Germany). The strain was stored at $-70^{\circ} \mathrm{C}$. The

112 organism was cultured for $48 \mathrm{~h}$ at $37^{\circ} \mathrm{C}$ on Columbia agar (Oxoid LTD, Basingstoke,

113 Hampshire, England) with 5\% sheep blood in a 5\% $\mathrm{CO}_{2}$ atmosphere. The ORT bacteria were

114 transferred into brain heart infusion broth (Oxoid) for $24 \mathrm{~h}$ at $37^{\circ} \mathrm{C}$ with agitation. The

115 bacterial challenge inoculum was prepared by washing the cultured bacteria twice in

116 phosphate-buffered saline (PBS) followed each time by five minutes of centrifugation at

$1173,000 \mathrm{rpm}$ at $4^{\circ} \mathrm{C}$. The resulting pellet was re-suspended in PBS to obtain a final

118 concentration of $8.6 \log _{10}$ colony-forming units $(\mathrm{cfu}) / \mathrm{ml}$. Confirmation of the number of

$119 \mathrm{cfu} / \mathrm{ml}$ was done by inoculating ten-fold dilutions in PBS on Columbia agar with 5\% sheep

120 blood and counting the number of colonies. The minimal inhibitory concentrations (MICs) of

121 amoxicillin, florfenicol and enrofloxacin for this challenge strain were $2 \mu \mathrm{g} / \mathrm{ml}, 1 \mu \mathrm{g} / \mathrm{ml}$ and

$122 \leq 0.03 \mu \mathrm{g} / \mathrm{ml}$, respectively, as determined according to Devriese et al. (2001). 
124 Antimicrobial agents. Three antimicrobial agents were used in this study: enrofloxacin

125 (Baytril $^{\circledR} 10 \%$ oral solution, Bayer, Leverkusen, Germany), amoxicillin (powder form)

126 (Suramox $50^{\circledR}$, soluble powder, Virbac S.A., Carros, France) and florfenicol (soluble form)

127 (Nuflor $^{\circledR}$, Schering-Plough S.A., Xochimilco, Mexico) with manufacturer-recommended

128 doses of $10 \mathrm{mg} / \mathrm{kg}$ for enrofloxacin and $20 \mathrm{mg} / \mathrm{kg}$ for amoxicillin and florfenicol.

130 Experimental design. Seventy-five SPF turkeys were randomly divided into 5 groups of 15

131 birds at one day of age.

132 In all groups, turkeys first received APV, and subsequently received $O R T$ three days later.

133 Each bird was inoculated with APV by the oculonasal route at a dose of $4.4 \log _{10} \mathrm{CD}_{50}$. ORT

134 was likewise administered oculonasally with a dosage of $8 \log _{10} \mathrm{cfu}$. For inoculation with

$135 \mathrm{APV}$ and $O R T$, a total of $250 \mu \mathrm{l}$ was divided equally over the nares and eyes. Four groups received antibiotic treatment: enrofloxacin $10 \mathrm{mg} / \mathrm{kg}$ for 3 days (group

137 E3), enrofloxacin $10 \mathrm{mg} / \mathrm{kg}$ for 5 days (group E5), florfenicol $20 \mathrm{mg} / \mathrm{kg}$ for 5 days (group F),

138 and amoxicillin $20 \mathrm{mg} / \mathrm{kg}$ for 5 days (group A). Starting at 24 hours post bacterial inoculation,

139 the drinking water was medicated with the appropriate antimicrobial agent. The birds were

140 continuously dosed and received their daily medication over a $24 \mathrm{~h}$ period. To enable correct

141 dosing, the daily water uptake and mean group body weights were determined. All turkeys

142 were weighed immediately before APV inoculation, before $O R T$ inoculation, at day 5 after

143 ORT inoculation, and finally at the end of the experiment (15 days post bacterial inoculation

144 (dpbi)). The concentration of each antibiotic to be administered in the water could be

145 calculated accurately on the basis of the water consumption and body weight data. The fifth

146 group was included as an untreated control group (group C).

147 All birds were clinically examined on a daily basis throughout the experiment. The

148 clinical signs were scored as described in Van de Zande et al. (2001). Briefly, the clinical 
149 condition of each bird was assigned a score from 0 (absence of clinical signs) to 7 (nasal

150 exudate with extremely swollen sinuses and frothy eyes, poor general condition and

151 anorexia). The mean clinical score was calculated for each experimental group. Tracheal swabs were collected from the animals in all groups at 3 days post viral

153 inoculation (dpvi) to confirm infection with APV, and daily until $11 \mathrm{dpbi}$ for $O R T$ titration.

154 The tracheal swabs were taken using cotton-tipped aluminium-shafted swabs (Copan

155 Diagnostics Inc., Corona, USA) and placed in $1 \mathrm{ml} \mathrm{PBS} \mathrm{supplemented} \mathrm{with} \mathrm{Ca}^{2+}$ and $\mathrm{Mg}^{2+}$

156 and in the case of virus titration an additional $10 \%$ fetal calf serum (Gibco, Invitrogen

157 Corporation, Merelbeke, Belgium), penicillin (1000 U/ml) (Biopharma, Rome, Italy) and

158 kanamycin $(0.5 \mathrm{mg} / \mathrm{ml})$ (Gibco). Processing occurred as described below.

159 Five birds of each group were randomly selected and were sacrificed at 5 dpbi. The

160 remaining 10 birds were sacrificed at $15 \mathrm{dpbi}$. The birds were necropsied and examined for

161 gross lesions. Samples of the turbinates, trachea, lungs, air sacs, heart and pericardium were

162 collected for bacterial isolation and processed immediately as described below. Finally,

163 samples from the turbinates, trachea and lungs were taken and fixed in $10 \%$ neutral buffered

164 formalin for histopathological examination.

165

166 Virological and bacteriological titration of tracheal swabs. The viral titre in $\log _{10} \mathrm{CD}_{50}$ per

$167 \mathrm{~g}$ mucus and the number of cfu of $O R T$ per g mucus were determined. This was done using

168 the procedures described in Marien et al. (2005).

170 Bacteriological titration of tissue suspensions and swabs. Samples of the turbinates,

171 trachea and lungs were titrated for $O R T$ from the 25 birds sacrificed at $5 \mathrm{dpbi}$. The number of

172 cfu of $O R T$ per g mucus was determined as described in Marien et al. (2005). 
174 sheep blood agar supplemented with $5 \mu \mathrm{g} / \mathrm{ml}$ gentamicin and $5 \mu \mathrm{g} / \mathrm{ml}$ polymyxin. After 24-

$17548 \mathrm{~h}$ of incubation at $37^{\circ} \mathrm{C}$ in $5 \% \mathrm{CO}_{2}$ atmosphere, the agar was examined for presence of

$176 O R T$. The same procedure was followed for samples from the turbinates, trachea, lungs, heart,

177 pericardium and air sacs from the birds sacrificed at $15 \mathrm{dpbi}$.

179 Histopathology. Following fixation in formalin, the tissues were embedded in paraffin, sectioned at $4 \mu \mathrm{m}$, mounted on glass slides and stained with haematoxylin and eosin using standard procedures. Tissues from the turbinates and trachea were additionally stained by the Periodic Acid Schiff-reaction in order to visualize the mucus layer. The degree of severity of the various histological lesions in the trachea and turbinates was assessed, including infiltration of heterophils and/or monomorphonuclear cells, degeneration of the mucous glands in the respiratory epithelium and damage to the ciliated epithelial cells and cilia). Each histological parameter was assigned a score from 0 (absence of particular lesion) to 4

187 (abundant presence of particular lesion).

MIC of the parent and re-isolated $O R T$ isolates. The MIC values of 124 ORT isolates retrieved from the tracheal swabs before, during and after antibiotic treatment were determined, specifically for the isolates from enrofloxacin group E3 and E5, for amoxicillin

192 group A and finally for florfenicol group F. Determination of the MIC values was performed as described by Devriese et al.

194 (2001), although modified slightly in that in this study MIC values were determined on

195 Mueller Hinton II agar (BBL, Sparks, MD, USA) supplemented with 5\% sheep blood. The 196 antibiotics used for the antimicrobial susceptibility test were enrofloxacin (Baytril ${ }^{\circledR} 10 \%$ oral

197 solution, Bayer, Leverkusen, Germany), amoxicillin (Suramox 50 ${ }^{\circledR}$, Virbac S.A., Carros, 
198 France) and florfenicol (Nuflor ${ }^{\circledR}$, Schering-Plough S.A., Xochimilco, Mexico). Final

199 concentrations ranging from 0.03 to $128 \mu \mathrm{g} / \mathrm{ml}$ (serial doubling dilutions) were tested.

200

201 Statistical analyses. The clinical scores and tracheal swabbing data of all animals were first

202 analyzed by a fixed-effects model with area under the curve between 0 and 5 dpbi as response

203 variable, and treatment group as fixed effect, to study the early effects of the infection based

204 on all treated animals.

205

Next, the repeated clinical scores between 0 and 9 dpbi, using only animals that were

206

207

208

209

210

211

212

213

214

215

216

217

218

219

220

221

\section{Results}

During the experiment, mortalities did not take place in any of the experimental groups. 
223 Clinical signs. The mean clinical score for each group is shown in Figure 1. Respiratory signs 224 were seen in all APV-inoculated groups starting from 3 dpvi. From 10 dpbi onwards, clinical signs were not detected in any of the animals in the different experimental groups. between the five treatments $(\mathrm{P}=0.0007)$. Group $\mathrm{C}$ has the highest total score $(10.33)$, followed by A, F, E5 and E3 (7). Significant differences are shown in Table 2. In the proportional odds model, both a significant change in time $(\mathrm{P}<0.0001)$ and a significant difference $(\mathrm{P}<0.0001)$ between the treatments were detected. E3 had the lowest odds ratio followed by E5, F, A and C.

Thus, compared with the non-treated control group, clinical signs were significantly reduced by the enrofloxacin treatments, irrespective of treatment duration, but not by treatment with florfenicol or amoxicillin.

Virological titration of tracheal swabs. APV was recovered from tracheal swabs from every individual bird. The mean titres for groups $\mathrm{C}$, E3, E5, A and F were 6.1, 5.9, 6.2, 5.8 and 6.1 $\log _{10} \mathrm{CD}_{50} / \mathrm{g}$ mucus, respectively.

Bacteriological titration of tracheal swabs. The results of the $O R T$ titrations of the tracheal swabs are shown in Figure 2. Mean titres as well as titres for each individual bird are depicted. From 11 dpbi onwards, ORT bacteria were not isolated in any of the animals in the different experimental groups. Using area under the curve in the fixed-effects model, there is a significant difference between the five treatments $(\mathrm{P}<0.0001)$, and in the mixed model, both a significant change in time $(\mathrm{P}<0.0001)$ and a significant difference between treatments $(\mathrm{P}<0.0001)$ were detected. In both analyses, group $\mathrm{C}$ has the highest total score followed by groups A, F, E5 and E3 and all 
seven pairwise comparisons ( $\mathrm{C}$ vs E3, $\mathrm{C}$ vs E5, E3 vs E5, E5 vs A, E5 vs F, E3 vs A, E3 vs F) are significant as indicated in Table 2.

tracheal mucus was hence significantly reduced by both enrofloxacin treatments (3- and 5-day treatment) and by the 5-day florfenicol treatment. Compared with the non-treated group, treatment with amoxicillin did not cause a significant reduction in the $O R T$ titres in the 254 trachea.

Bacteriological titration of tissue samples. The results of $O R T$ titrations in the various organs sampled at 5 dpbi are shown in Table 1. It should be noted that the clinical signs were very similar in terms of severity in all five euthanised birds of one group. For results from the turbinates, trachea and lungs, there were significant differences between the treatments $(\mathrm{P}<0.0001)$. Pairwise significant differences are shown in Table 2. Compared with the nontreated control group, the number of $O R T$ in the trachea and lungs was significantly reduced by the enrofloxacin treatments and by the florfenicol treatment, as opposed to treatment with amoxicillin. Furthermore, the number of $O R T$ isolated from the turbinates was significantly reduced by the 3-day enrofloxacin treatment. For the air sacs, pericardium and heart, very few positive samples were encountered (in group $\mathrm{C}$ and group $\mathrm{A}$ ), and significant differences between the treatments did not occur. ORT was recovered from none of the organs (turbinates, trachea, lungs, pericardium, 268 and air sacs) of the birds in the five groups swabbed at $15 \mathrm{dpbi}$.

270 Histopathology. Similar microscopical changes were encountered in all experiment groups.

271 In the mucosa of the turbinates and the trachea, a mixed inflammatory reaction was seen.

272 Furthermore, focal loss of cilia and/or necrosis of the epithelium, as well as degeneration of 
273 mucous glands, were found in the turbinates and trachea. In the lung samples focal areas of 274 bronchitis and bronchiolitis were observed. No significant difference between the five treatments was found for any of the 276 different parameters considered.

278 Weight. Significant differences occurred between the different treatments $(\mathrm{P}<0.0001)$.

279 Weight evolves differently over time from treatment to treatment, i.e., there is a significant 280 interaction between time and treatment $(\mathrm{P}<0.0001)$. Pairwise significant differences $(0.7 \%)$ 281 are shown in Table 2.

283 Antimicrobial therapy. The theoretically consumed dose of antibiotics per group of birds 284 was very close (within 10\%) to the target dose of $10 \mathrm{mg} / \mathrm{kg}$ for enrofloxacin and $20 \mathrm{mg} / \mathrm{kg}$ for 285 amoxicillin and florfenicol. The mean actual daily dose $(\mathrm{mg} / \mathrm{kg})$ for the total medication 286 period was 10.2 (range: 9.1-11.3) for group E3, 10.2 (range: 9.4-11.9) for group E5, 20.4 287 (range: 19.0-22.5) for group F, and 19.9 (range: 17.5-22.7) for group A.

MIC of the parent and re-isolated $O R T$ isolates. In the $O R T$ bacteria re-isolated from birds in groups $\mathrm{C}, \mathrm{E} 3, \mathrm{~A}$ and $\mathrm{F}$, no changes in MIC values were observed compared with the challenge strain. However, 2 days after initiation of enrofloxacin treatment onwards, the MICs of the ORT bacteria isolated from tracheal swabs from group E5 had values that 293 increased from 0.03 to $0.25 \mu \mathrm{g} / \mathrm{ml}$.

Discussion

296 This study is the first to experimentally investigate the clinical efficacy of different 297 antimicrobial therapies for treatment of dual APV/ORT infection in turkeys. Statistical 
analysis of the obtained results revealed that under the circumstances used in this study, recovery from respiratory disease caused by APV/ORT dual infection in 3-week-old turkeys was most successful overall after enrofloxacin treatment ( 3 or 5 days of treatment), followed by florfenicol treatment. Clinical signs as well as the number of $O R T$ bacteria recovered from the trachea and different respiratory organs (turbinates, trachea and lungs), were significantly reduced by enrofloxacin treatment for 3 or 5 days, compared with the non-treated group.

304 Compared with the non-treated group, 5-day treatment with amoxicillin did not cause a significant reduction in any of the afore mentioned parameters and although 5-day florfenicol treatment significantly diminished the amount of $O R T$ isolated out of the trachea and lungs, this did not seem to result in a significant reduction in clinical symptoms. These results are in 308 accordance with data presented by Froyman \& Cooper (2003), who demonstrated that 309 enrofloxacin treatment was most efficacious for the treatment of colisepticemia in chickens, 310 followed by florfenicol, and that amoxicillin was not effective.

A possible explanation for the observed differences between antimicrobials relates to

312 their different pharmacokinetic and pharmacodynamic properties. An important

313 pharmacokinetic parameter for assessing the ability of antibiotic agents to distribute

314 throughout the tissues is the apparent volume of distribution at steady state $(\operatorname{Vd}(s s)) . V d_{(s s)}$ 315 gives an indication of the diffusion of the active antimicrobial compound in the body tissues.

316 A relatively low $V d_{(s s)}$ value indicates a drug that is less extensively distributed in 317 extravascular tissues. Different pharmacokinetic studies with enrofloxacin, florfenicol and 318 amoxicillin in either turkeys or chickens have been performed (Carceles et al., 1995; Anadón 319 et al., 1996; Rios et al., 1997; Bugyei et al., 1999; Knoll et al., 1999; Shen et al., 2003; Cox et 320 al., 2004; Switala et al., 2004; Dimitrova et al., in press). From these studies, it may be 321 concluded that the $V d_{(s s)}$ of amoxicillin $(0.042-1.521 / \mathrm{kg})$ is generally lower than that of

322 florfenicol (1.5 - $4.991 / \mathrm{kg})$ and enrofloxacin $(2.92-3.91 / \mathrm{kg})$. 
323 Another perhaps influential parameter may be the elimination half-life of the different

324 antibiotics. When comparing half-life values determined in different experiments, it may be 325 concluded that enrofloxacin has long half-life values (Brown, 1996; Bugyei et al., 1999;

326 Garcia Ovando et al., 1999; Knoll et al., 1999; Dimitrova et al., in press) and that the values

327 for florfenicol are generally lower (Afifi \& El-Sooud, 1997; Shen et al., 2002; Shen et al.,

328 2003), with the lowest half-life values noted for amoxicillin (Lashev \& Pashov, 1992;

329 Carceles et al., 1995; Anadon et al., 1996). Although both enrofloxacin and amoxicillin have 330 good bactericidal activity, as opposed to florfenicol which is bacteriostatic, e.g., for E. coli 331 and Salmonella spp. (Graham et al., 1988), it seems that the bactericidal effect of amoxicillin

332 is impaired because it is less efficiently distributed throughout the tissues and in addition is

333 eliminated quickly (Goren et al., 1981). The prominent results for enrofloxacin may be

334 explained by its rapid bactericidal activity at relatively low concentrations (Brown, 1996) and

335 its excellent distribution throughout tissues for longer periods of time (Brown, 1996;

336 McKellar, 1996).

The CLSI (formerly NCCLS) breakpoints for amoxicillin vary greatly according to the

338 bacteria involved. For instance, enterobacteriaceae are considered to be resistant when they

339 have MIC values as high as $32 \mu \mathrm{g} / \mathrm{ml}$ or more, whereas staphylococci are already designated

340 as resistant with MIC values of $0.5 \mu \mathrm{g} / \mathrm{ml}$ or more (CLSI guidelines, 2002). No CLSI

341 breakpoints have been established for $O R T$, but from the results of the present investigation it

342 can be concluded that an infection caused by $O R T$ strains with an MIC of $2 \mu \mathrm{g} / \mathrm{ml}$, does not

343 seem to respond to antibiotic treatment with amoxicillin. According to Devriese and

344 colleagues (2001) who tested 45 ORT strains from poultry, MIC values for ampicillin

345 generally varied between 1 and $8 \mu \mathrm{g} / \mathrm{ml}$. According to Bush (2003), the antibacterial spectrum

346 of amoxicillin is identical to that of ampicillin and there are few differences in antibacterial

347 activity, especially against Gram-negative bacteria. 
No increase in the amoxicillin or florfenicol MIC value for the bacteria re-isolated

349 from the respective groups was noted. Likewise, no change in antibiotic sensitivity was

350 observed in $O R T$ bacteria reisolated from group E3. In group E5, no ORT could be isolated

351 after the $1^{\text {st }}$ day after onset of treatment, but on the second day of the 5-day treatment course,

$352 O R T$ organisms with an eight-fold higher MIC value (from $\leq 0.03$ to $0.25 \mu \mathrm{g} / \mathrm{ml}$ ) were

353 isolated, first from one turkey, then successively from the other penmates. This increase in

354 enrofloxacin MIC value concurred with a slight $O R T$ re-excretion in the trachea, also reflected

355 in the higher counts in different organs (turbinates and lungs) at 5 dpbi, compared with the

356 almost negative $O R T$ counts post-treatment in the turkeys treated for 3 days.

The re-emergence of $O R T$ isolates with increased MIC value was first seen in one

animal on day two of antibiotic treatment, and subsequently, each following day, isolates with

359 increased MIC were found in more birds (data not shown). This may suggest that the less

360 susceptible $O R T$ isolate might have spread from one turkey to other penmates, although

361 further epidemiological studies need to be performed to confirm this. Since ORT isolates with

362 a rise in MIC value were already found after two days of enrofloxacin treatment, this suggests

363 that this rise in MIC may also have occurred in the 3-day treatment group.

364 Although the MIC of the re-isolated bacteria increased from $\leq 0.03$ to $0.25 \mu \mathrm{g} / \mathrm{ml}$, the

365 ORT isolates are not to be considered resistant to enrofloxacin (Devriese et al., 2001; CLSI

366 guidelines, 2002). The term "reduced susceptibility" is more appropriate to characterize the

367 antibiotic sensitivity status of the isolates with an eight-fold increase in MIC value. It should

368 be noted that in the present study, this emergence of decreased sensitivity did not lead to a

369 clinical relapse. Experimental infection studies, including the fully susceptible $O R T$ strain and

370 the $O R T$ strain with slightly higher MIC value, would be necessary to be able to conclude

371 anything about the impact of this MIC rise on the in vivo efficacy of enrofloxacin. Froyman \&

372 Cooper (2003) reported that in chickens, enrofloxacin was less efficacious for the treatment of 
373 disease caused by an E. coli strain with reduced sensitivity (MIC of $0.5 \mu \mathrm{g} / \mathrm{ml}$ ) when

374 compared with the treatment of disease caused by a fully sensitive E. coli strain (MIC of $3750.015 \mu \mathrm{g} / \mathrm{ml})$.

376

\section{Acknowledgements}

This work was supported by a grant from Bayer HealthCare AG, Animal Health. The authors would like to express their appreciation to Venessa Eeckhaut, Arlette Van de Kerckhove,

Carine Boone and Christian Puttevils for their skilled technical assistance. Furthermore, we

would like to thank Dr. M. Hafez (Institute of Poultry Diseases, Free University of Berlin,

383 Germany) for serotyping the ORT strain used and Mr. B. Van Dam (BioChek) for supplying 384 the ELISA.

\section{References}

Afifi, N.A. \& El-Sooud, K.A. (1997). Tissue concentrations and pharmacokinetics of florfenicol in broiler chickens. British Poultry Science, 38, 425-428.

Anadón A, Martinez-Larrañaga, M.R., Diaz, M.J., Bringas, P., Fernandez, M.C., Martinez, M.A. \& Fernandez-Cruz, M.L. (1996). Pharmacokinetics of amoxicillin in broiler chickens. Avian Pathology, 25, 449-458.

Brown, S.A. (1996). Fluoroquinolones in animal health. Journal of Veterinary Pharmacology and Therapeutics, 19, 1-14.

Bugyei, K., Black, W.D. \& McEwen, S. (1999). Pharmacokinetics of enrofloxacin given by the oral, intravenous and intramuscular routes in broiler chickens. Canadian Journal of Veterinary Research, 63, 193-200. 
398 Bush, K. (2003). B-Lactam antibiotics: penicillins. In Antibiotic and chemotherapy, $8^{\text {th }}$ edition. Finch R.G., Greenwood D., Norrby S.R., and Whitley R.J. (ed.), Churchill Livingstone, New York.

Carceles, C.M., Vicente, M.S. \& Escudero, E. (1995). Pharmacokinetics of amoxicillinclavulanic acid combination after intravenous and intramuscular administration to turkeys and chickens. Avian Pathology, 24, 643-952.

CLSI guidelines (2002). Performance Standards for Antimicrobial Disk and Dilution Edition. NCCLS document M31-A2 (pp. 55-59). NCCLS, Pennsylvania, USA.

Cox, S.K., Cottrell, M.B., Smith, L., Papich, M.G., Frazier, D.L. \& Bartges, J. (2004). Allometric analysis of ciprofloxacin and enrofloxacin pharmacokinetics across species. Journal of Veterinary Pharmacology and Therapeutics, 27, 139-146.

Devriese, L.A., De Herdt, P. \& Haesebrouck, F. (2001). Antibiotic sensitivity and resistance in Ornithobacterium rhinotracheale strains from Belgian broiler chickens. Avian Pathology, 30, 197-200.

Dimitrova, D.J., Lashev, L.D., Janev, St.G. \& Pandova, V.D. Pharmacokinetics of enrofloxacin and its metabolite ciprofloxacin in male and female turkeys following intravenous and oral administration. In press, Veterinary Research Communications.

Froyman, R. \& Cooper, J. (2003). Assessment of the efficacy of fluoroquinolones and other antimicrobials against respiratory colibacillosis and septicemia in chickens under standardized challenge conditions. In Proceedings of the XIII Congress of the WPVA (pp. 84). Denver, Co, US.

Garcia Ovando, H., Gorla, N., Luders, C., Poloni, G., Errecalde, C., Prieto, G. \& Puelles, I. (1999). Comparative pharmacokinetics of enrofloxacin and ciprofloxacin in chickens. 
423 Goren, E., De Jong, W.A. \& Van Solkema, A. (1981). Some pharmacokinetical aspects of ampicillin trihydrate and its therapeutic efficacy in experimental Escherichia coli infection in poultry. Avian Pathology, 10, 43-55.

Graham, R., Palmer, D., Pratt , B.C. \& Hart, C.A. (1988). In vitro activity of florphenicol. European Journal of Clinical Microbiology and Infectious Diseases, 7, 691-694.

Hafez, H.M. \& Sting, R. (1999). Investigations on different Ornithobacterium rhinotracheale “ORT” isolates. Avian Diseases, 34 (1), 1-7.

Knoll, U., Glünder, G. \& Kietzmann, M. (1999). Comparative study of the plasma pharmacokinetics and tissue concentrations of danofloxacin and enrofloxacin in broiler chickens. Journal of Veterinary Pharmacology and Therapeutics, 22, 239-246.

Lashev, L.D. \& Pashov, D.A. (1992). Interspecies variations in plasma half-life of ampicillin, amoxicillin, sulphadimidine and sulphacetamide related to variations in body mass. Research in Veterinary Science, 53, 160-164.

McKellar, Q.A. (1996). Clinical relevance of the pharmacologic properties of fluoroquinolones. Compendium on Continuing Education for the Practicing Veterinarian, 18 (2), 492-497.

Marien, M., Decostere, A., Martel, A., Chiers, K., Froyman, R. \& Nauwynck, H. (2005). Synergy between avian pneumovirus and Ornithobacterium rhinotracheale in turkeys. Avian Pathology, 34 (3), 204-211.

Rios, A., Martínez-Larrañaga, M.R. \& Anadón, A. (1997). Plasma disposition of florfenicol in broiler chickens following intravenous administration. Journal of Veterinary Pharmacology and Therapeutics, 20 (Supplement 1), 182.

Shen, J., Wu, X., Hu, D. \& Jizng, H. (2002). Pharmacokinetics of florfenicol in healthy and Escherichia coli-infected broiler chickens. Research in Veterinary Science, 73, 137140. 
448 Shen, J., Hu, D., Wu, X. \& Coats, J.R.. (2003). Bioavailability and pharmacokinetics of

449

450

451

452

453

454

455

456

457

458

459

460

461

462

463

464

465

466

467

468

469

470 florfenicol in broiler chickens. Journal of Veterinary Pharmacology and Therapeutics, 26, 337-341.

Switala, M., Okoniewski, P., Smutkiewicz, A., Jaworski, K. \& Hrynyk, R.. (2004). Pharmacokinetics of florfenicol and thiamphenicol in turkeys. In Proceedings of the Second international conference on antimicrobial agents in veterinary medicine (AAVM) (p. 99). Ottawa, Canada.

Van de Zande, S., Nauwynck, H., Cavanagh, D. \& Pensaert, M. (1998). Infections and reinfections with avian pneumovirus subtype A and B on Belgian turkey farms and relation to respiratory problems. Journal of Veterinary Medicine Series B, 45 (10), 621-626.

Van de Zande, S., Nauwynck, H. \& Pensaert, M. (2001). The clinical, pathological and microbiological outcome of an Escherichia coli $\mathrm{O} 2: \mathrm{K} 1$ infection in avian pneumovirus infection in turkeys. Veterinary Microbiology, 81, 353-365.

van Empel, P., van den Bosch, H., Goovaerts, D., \& Storm, P. (1996). Experimental infection in turkeys and chickens with Ornithobacterium rhinotracheale. Avian Diseases, 40, 858-864.

van Empel, P.C.M. \& Hafez, H.M. (1999). Ornithobacterium rhinotracheale: a review. Avian Pathology, 28, 217-227.

Van Loock, M., Geens, T., De Smit, L., Nauwynck, H., van Empel, P., Naylor, C., Hafez, H.M., Goddeeris, B.M. \& Vanrompay, D. (2005). Key role of Chlamydophila psittaci on Belgian turkey farms in association with other respiratory pathogens. Veterinary Microbiology, 107, 91-101. 
Table 1. Bacterial titre ( $\log _{10}$ cfu/g tissue) of ORT in different organs of turkeys inoculated with APV and ORT with an interval of three days and treated with different antibiotic therapies: group E3, 3 days of enrofloxacin (10 mg/kg); group E5, 5 days of enrofloxacin (10 mg/kg); group A, 5 days of amoxicillin $(20 \mathrm{mg} / \mathrm{kg}$ ); group F, 5 days of florfenicol $(20 \mathrm{mg} / \mathrm{kg})$, or no treatment (group C). Turkeys were euthanised at 5 dpbi.

\begin{tabular}{|c|c|c|c|c|c|c|c|c|c|c|c|c|c|c|c|c|c|c|c|c|c|c|c|c|c|}
\hline \multirow{3}{*}{ Organ } & \multicolumn{25}{|c|}{ Mean $O R T$ titre $\left(\log _{10} \mathrm{cfu} / \mathrm{g}\right.$ tissue $)$} \\
\hline & \multicolumn{5}{|c|}{ Group C } & \multicolumn{5}{|c|}{ Group E3 } & \multicolumn{5}{|c|}{ Group E5 } & \multicolumn{5}{|c|}{ Group A } & \multicolumn{5}{|c|}{ Group F } \\
\hline & $1^{\mathrm{a}}$ & 2 & 3 & 4 & 5 & 1 & 2 & 3 & 4 & 5 & 1 & 2 & 3 & 4 & 5 & 1 & 2 & 3 & 4 & 5 & 1 & 2 & 3 & 4 & 5 \\
\hline Turbinates & 8.5 & 8.4 & 6.9 & 11 & 8.4 & 0 & 0 & 4.9 & 0 & 0 & 5 & 7.1 & 7.5 & 4.3 & 4.5 & 8.4 & 8.6 & 8.6 & 7 & 6.3 & 10 & 8 & 9.2 & 6.4 & 7.3 \\
\hline Trachea & 7.9 & 7.3 & 7.8 & 7.5 & 7.6 & 0 & 0 & 0 & 0 & 0 & 4.2 & 6.5 & 6.2 & 4.5 & 4.1 & 7.5 & 7.5 & 8.3 & 6.9 & 7.6 & 5.3 & 7.5 & 4.8 & 5.1 & 6.1 \\
\hline Lungs & 6.1 & 5.8 & 6 & 6.7 & 0 & 0 & 0 & 0 & 0 & 0 & 0 & 3.2 & 0 & 2.8 & 2.9 & 6.8 & 5.5 & 4.6 & 6.3 & 6.4 & 3.3 & 0 & 2.2 & 3.5 & 0 \\
\hline Air sacs ${ }^{b}$ & - & + & - & + & + & - & - & - & - & - & - & - & - & - & - & - & - & - & - & + & - & - & - & - & - \\
\hline Pericardium $^{\mathrm{b}}$ & - & - & - & - & - & - & - & - & - & - & - & - & - & - & - & - & - & - & - & - & - & - & - & - & - \\
\hline Heart $^{b}$ & - & + & - & - & + & - & - & - & - & - & - & - & - & - & - & + & - & - & - & + & - & - & - & - & - \\
\hline
\end{tabular}

a: number of turkey

b: these organs were swabbed; - no ORT was isolated / + at least one cfu of ORT was recovered. 
Table 2. Statistical analyses of clinical scores, tracheal swabbing, isolation of ORT from organs and weight of turkeys inoculated with APV and ORT with an interval of three days and treated with different antibiotic therapies: group E3, 3 days of enrofloxacin (10 mg/kg); group E5, 5 days of enrofloxacin (10 mg/kg); group A, 5 days of amoxicillin (20 mg/kg); group F, 5 days of florfenicol (20 mg/kg), or no treatment (group C).

\begin{tabular}{|c|c|c|c|c|c|c|c|c|}
\hline & \multicolumn{2}{|c|}{ Clinical score } & \multicolumn{2}{|c|}{$\begin{array}{l}\text { Isolation of } O R T \text { from tracheal } \\
\text { mucus }\end{array}$} & \multicolumn{3}{|c|}{$\begin{array}{c}\text { Isolation of } O R T\left(\log _{10} \mathrm{cfu} / \mathrm{g} \text { tissue }\right) \\
\text { at } 5 \mathrm{dpbi} \text { from }\end{array}$} & \multirow{2}{*}{$\begin{array}{c}\text { Weight } \\
\text { in } \mathrm{g}\end{array}$} \\
\hline Group & $\begin{array}{l}\text { Area under the } \\
\text { curve (from } 0 \\
\text { to } 5 \mathrm{dpbi}^{* 1} \text { ) }\end{array}$ & $\begin{array}{l}\text { (with group C } \\
\text { as reference } \\
\text { group) (from } 0 \\
\text { to } 9 \mathrm{dpbi} \text { ) }\end{array}$ & $\begin{array}{l}\text { Area under the } \\
\text { curve (from } 0 \\
\text { to } 5 \mathrm{dpbi} \text { ) }\end{array}$ & $\begin{array}{l}\log _{10} \mathrm{cfu} / \mathrm{g} \\
\text { mucus (from } \\
0 \text { to } 9 \mathrm{dpbi})\end{array}$ & Turbinate & Trachea & Lungs & \\
\hline $\mathrm{C}$ & $10.33(0.58)^{*^{2 \mathrm{~A}}}$ & $1^{\mathrm{A}}$ & $25.86(0.61)^{\mathrm{A}}$ & $4.51(0.23)^{\mathrm{A}}$ & $8.64(0.71)^{\mathrm{A}}$ & $7.62(0.34)^{\mathrm{A}}$ & $4.92(0.75)^{\mathrm{A}}$ & $578.40(12.54)^{\mathrm{A}}$ \\
\hline A & $9.45(0.57)^{\mathrm{AB}}$ & $0.78(0.32)^{\mathrm{A}}$ & $25.76(0.59)^{\mathrm{A}}$ & $4.40(0.22)^{\mathrm{A}}$ & $7.78(0.71)^{\mathrm{A}}$ & $7.56(0.34)^{\mathrm{A}}$ & $5.92(0.34)^{\mathrm{A}}$ & $582.67(12.09)^{\mathrm{A}}$ \\
\hline $\mathrm{F}$ & $8.57(0.58)^{\mathrm{AC}}$ & $0.43(0.16)^{\mathrm{AB}}$ & $15.82(0.68)^{\mathrm{B}}$ & $3.05(0.23)^{\mathrm{B}}$ & $8.22(0.71)^{\mathrm{A}}$ & $5.76(0.34)^{\mathrm{B}}$ & $1.80(0.34)^{\mathrm{B}}$ & $626.19(12.39){ }^{\mathrm{AB}}$ \\
\hline E5 & $7.67(0.58)^{\mathrm{BC}}$ & $0.30(0.11)^{\mathrm{BC}}$ & $7.94(0.61)^{\mathrm{C}}$ & $2.14(0.23)^{C}$ & $5.68(0.71)^{\mathrm{A}}$ & $5.10(0.34)^{\mathrm{BC}}$ & $1.78(0.34)^{\mathrm{B}}$ & $654.53(12.24)^{B}$ \\
\hline E3 & $7.00(0.59)^{\mathrm{C}}$ & $0.21(0.08)^{\mathrm{C}}$ & $4.84(0.55)^{\mathrm{D}}$ & $1.05(0.24)^{\mathrm{D}}$ & $0.98(0.71)^{\mathrm{B}}$ & $0.00(0.34)^{\mathrm{D}}$ & $0.00(0.34)^{\mathrm{B}}$ & $600.52(13.12)^{\mathrm{A}}$ \\
\hline
\end{tabular}

$*^{1}$ : dpbi: days post bacterial inoculation

$*^{2}$ : Mean value (standard error)

$\mathrm{ABCD}$ : Treatments sharing a letter do not differ significantly from one another at the 5\% global significance level. 
Figure 1. Mean clinical scores in turkeys inoculated with APV and ORT and subsequently treated with different antimicrobial agents: - group E3, 3 days of enrofloxacin $(10 \mathrm{mg} / \mathrm{kg})$;

- group E5, 5 days of enrofloxacin (10 mg/kg); $\mathbf{\Delta}$ group A, 5 days of amoxicillin (20 $\mathrm{mg} / \mathrm{kg})$;

$\times$ group $F, 5$ days of florfenicol $(20 \mathrm{mg} / \mathrm{kg})$ or no treatment $=\diamond$ control group. Arrow indicates first day of antibiotic treatment.

Figure 2. Bacterial titres ( $\log _{10}$ cfu/g mucus) in tracheal mucus collected at different times after ORT inoculation in APV/ORT dually infected turkeys receiving different antibiotic treatments: - group E3, 3 days of enrofloxacin, (10 $\mathrm{mg} / \mathrm{kg})$; $\bullet$ group E5, 5 days of enrofloxacin $(10 \mathrm{mg} / \mathrm{kg}) ; \mathbf{\Delta}$ group A, 5 days of amoxicillin $(20 \mathrm{mg} / \mathrm{kg}) ; \times$ group $F, 5$ days of florfenicol (20 mg/kg), or no treatment ( control group). (Individual values are indicated with small symbols; means are indicated with larger symbols.) Arrow indicates first day of antibiotic treatment. 
Figure 1

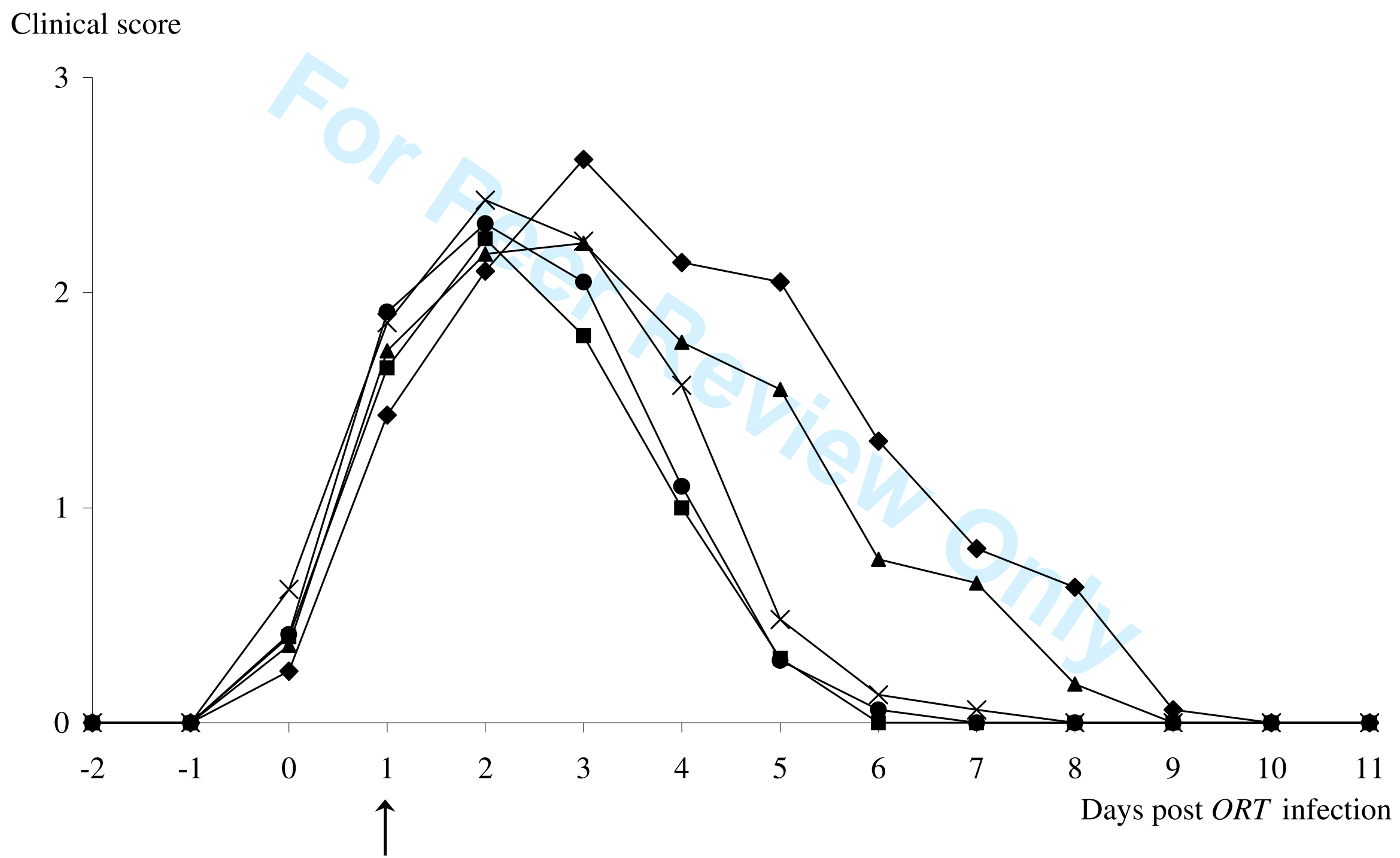


Figure 2.

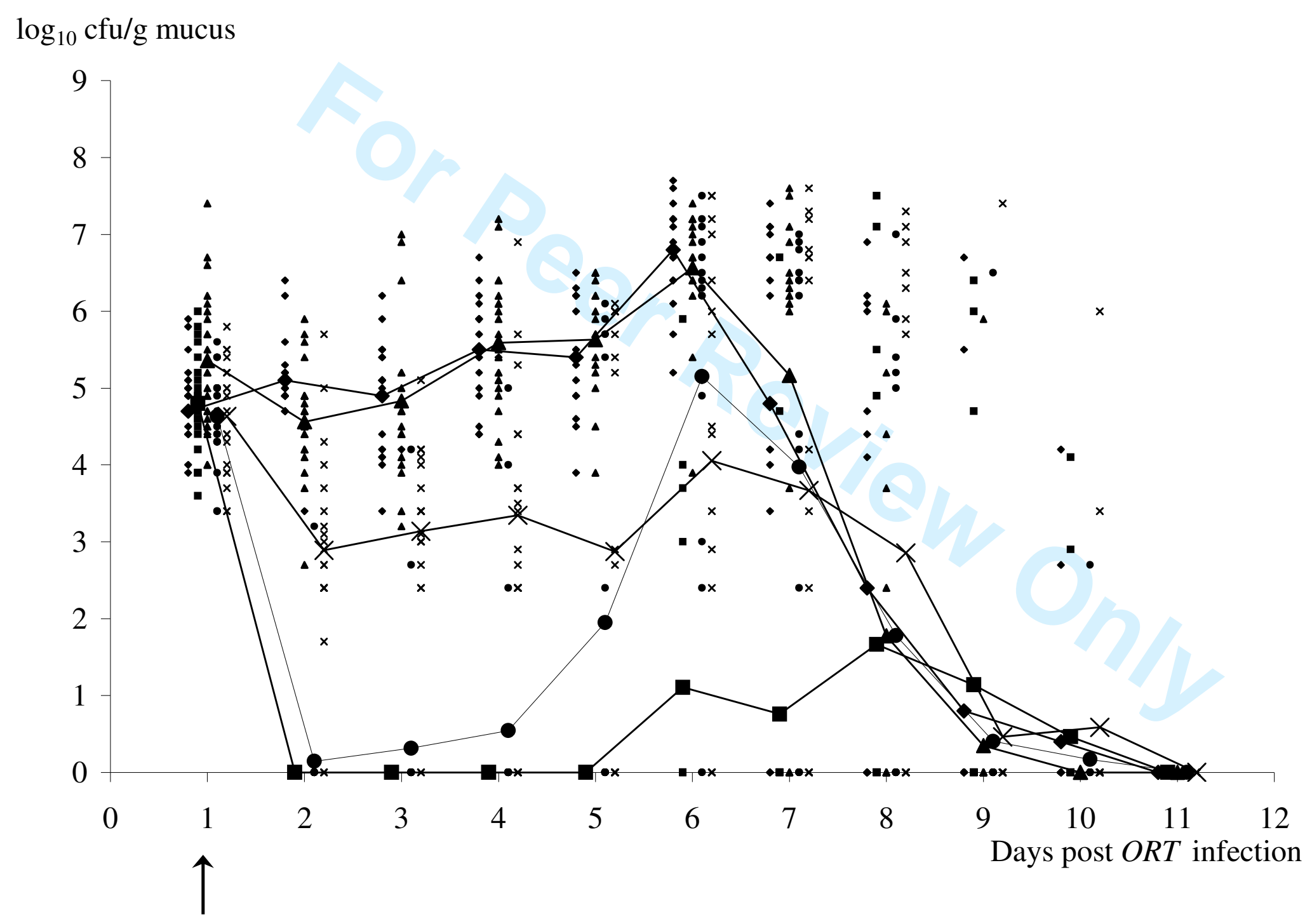

